\title{
Party at the Mailbox: Mobilizing Black Voters with Celebrations of Community
}

Ashley C.J. Daniels, Howard University

Stephanie L. DeMora, University of California, Riverside

Sarah Hayes, Georgetown University

Melissa R. Michelson, Menlo College

\begin{abstract}
In early 2020, as Democrats were still choosing their presidential nominee, the U.S. was shuttered by COVID-19. Voters in many remaining primaries and for the general election had to find means of voting safely. In Baltimore, Black Girls Vote, Inc. (BGV) created an initiative to deliver customized locally-themed voter engagement boxes to city residents. In cooperation with $\mathrm{BGV}$, our academic team developed a randomized controlled trial to test the effectiveness of the project, supplemented with survey, interview, and focus group data. The pilot Party at the Mailbox (PATM) effort for the June 2020 primary was enormously successful, increasing turnout by 3.5 percentage points overall and by 12.4 percentage points among low-propensity members of households where boxes were delivered. We continued to partner with BGV for the fall general elections as they again worked to increase turnout in Baltimore and also expanded to Detroit and Philadelphia, and for the January 2021 U.S. Senate runoff election in Atlanta. We use mixed methods data to test our theories about when and why PATM increased turnout. We conclude that PATM works because it cultivates a spirit of celebration about voting that capitalizes on Black group consciousness and Black attitudes about the power of the vote.
\end{abstract}

Prepared for delivery at the 2021 annual meeting of the American Political Science Association. Please do not cite without permission from the authors. 
Decades of get-out-the-vote (GOTV) research has explored various methods, messages, and messengers for insights as to which aspects of these campaigns are most effective, and when. Among the lessons learned are that the mechanisms for increasing turnout are linked to identity — eligible citizens are likely to vote as expressions of their ingroup identities, and messengers that share an ingroup identity with the target voter are more effective than outgroup messengers. Turnout is thus perhaps best understood as a behavior not necessarily undertaken as an instrumental activity, but as an expressive one. Turnout is also enhanced by election festivals: events that make voting a celebratory community event. In this paper, we explore the power of an innovative GOTV tactic that channeled multiple layers of identity and a spirit of community celebration to increase turnout in majority-Black communities across four states and three elections. The results build on a small but clear body of scholarship focused on GOTV among Black voters, finding that Black voters are effectively mobilized by efforts that link their racial and geographic identities in a celebration of community.

History and political science scholars have demonstrated that turnout is enhanced by cultivating a festive community celebration around elections. For the first half century of the new United States, voting was done by voice and in public, and with a festive atmosphere. "Elections were a chance to weigh in on important business, but they were also an opportunity to let loose and party" (Blakemore 2019). Turnout was also extremely high, sometimes reaching $85 \%$ of eligible voters. In contrast, voting today is done privately and sedately, and turnout is far lower. Those seeking to increase participation have tested a variety of tactics and messages, including "election festivals" (Addonizio, Green, and Glazer 2007; Green and McClellan 2017, 2020). Making elections a celebratory community event can increase turnout; but, while everyone loves a party, they are not always feasible or appropriate. In 2020 in particular, precautions taken to 
keep voters safe during the pandemic included reduced in-person voting options and an increased emphasis on vote-by-mail.

We hypothesized that efforts to mobilize voters by cultivating a celebratory community environment would be particularly successful in majority-Black communities, given the strong tradition among many Black Americans of voting as a celebration of community. Since the Reconstruction era, Black American organizations and institutions have maintained a rich history of mobilizing their communities to vote. Black Americans have a unique political socialization where most of their political cues are generated at the grassroots level among familial and community spaces (Walton 1985; Lee 2002; Harris-Lacewell 2004; Walton and Smith 2012). As a result, Black Americans view voting as an important activity or value to uphold in community.

Groups such as churches, social fellowships, fraternities and sororities, suffrage clubs, and other organizations have taken an active part in not only advocating for Black Americans' right to vote but encouraging their communities to exercise that right with community events and meetings including voter registration efforts and town halls (Giddings 1984; Giddings 1989; Higginbotham 1993; Smooth 2018; Daniels 2020, 2021). Building upon this practice, these types of organizations have developed new and innovative ways to engage potential voters within the past several decades. Black churches have worked for 60 years to increase voter turnout, more recently under slogans such as "souls to the polls" (Daniels 2020). The effectiveness of these church-based programs can be seen in research showing that Black early voting turnout in Florida spikes on Sundays (Herron and Smith 2012).

In 2020, this celebratory community spirit was particularly evident among members of Alpha Kappa Alpha, a Black sorority that Democratic vice-presidential nominee Kamala Harris joined as a student at Howard University, as well as members of the other Black fraternities and 
sororities which make up the Divine Nine. The Washington Post reported October 1, 2020 that sorority members were celebrating Harris's nomination and working to increase turnout among members (Janes 2020). Our partner organization, Black Girls Vote, Inc., shares the same historical lineage of these organizations, particularly Black women-led organizations, who create unique programs and initiatives to engage Black voters (Vroman 1965; Giddings 1984; Higginbotham 1993; Collins 2000; Dowe 2016; Smooth 2018).

Voter mobilization research has tended to focus on general (non-Latinx white) populations, and less is known about how best to mobilize some demographic groups, including Black Americans. This gap in existing scholarship is attributable to two major factors. First, Black voters have traditionally been strong supporters of the Democratic Party, and also located in non-competitive geographic areas, thus reducing interest in how best to increase their levels of participation. Most Black voters do not receive invitations to participate. Even in battleground states, people of color are less likely to be mobilized compared to white voters (Ramírez, Solano, and Wilcox-Archuleta 2018). Excluding the presidential races that included Barack Obama, Black turnout generally is low (Fraga 2018). In part this reflects strategic decisions made by candidates and campaigns, who know that Black voters can be relied upon as loyal Democratic voters (Frymer 1999; White and Laird 2020).

The dearth of published work on how best to mobilize Black voters is significant because of the increasingly visible role played by Black voters in U.S. politics, as evidenced by the results of the 2020 presidential elections, and also because we should not assume the relevance of best practices generated from GOTV efforts in non-Black communities. As Michael Dawson (1994) notes, “African-American politics, including political behavior, is different. It has been shaped by historical forces that produced a different pattern of political behavior from the pattern 
found among white citizens" (p. 5). This different pattern of behavior is attributed to what Dawson calls linked fate: that the historical experiences of African Americans lead them to use group interests as a proxy for self-interest. Individuals will consider racial group interests when making political choices when they believe their own life chances are linked to those of Black Americans as a group.

Second is the lack of data collected and analyzed about Black Americans on this topic. Typically, there is rational reluctance by many in the Black community, given the unethical historical examples Henrietta Lacks and Tuskegee, to name just a few, to cooperate with outside researchers seeking to experiment on their communities. Within the past several decades, scholars have worked to address this issue with varying outcomes. Between 1984 and 1996, a team of researchers at the University of Michigan conducted the National Black Election Study (NBES) which collected interviews from thousands of Black Americans about their political thoughts and beliefs. The data generated from this study continues to be used by those interested in Black public opinion, in part due to the dearth of more recent alternatives. After the GOTV experimental subfield was relaunched in 2000 (Gerber and Green 2000), scholars around the country sought to extend those findings with randomized controlled trials in different geographic areas and with different communities. Early efforts focusing on Black voters included mostly indirect tactics: a November 2000 collaboration with the National Association for the Advancement of Colored People (NAACP) using direct mail and commercial phone banks (Green 2004), leafleting campaigns in partisan races (Gillespie 2005), and nonpartisan campaigns targeting predominantly Black precincts (Azari and Washington 2006). These initial efforts, however, generated negligible effects on participation. 
Door-to-door canvassing efforts by local community organizations, in contrast, have consistently increased Black voter turnout. This includes efforts conducted by the now-defunct Association of Community Organizations for Reform Now (ACORN) in November 2001 in Detroit, MI and in November 2003 in Kansas City, MO. The target populations in these cities at the time were 94\% and 64\% African American, respectively. Contact with an ACORN canvasser increased turnout in these RCTs by 7.8 percentage points in Detroit and by 8.5 percentage points in Kansas City (Green and Michelson 2009). RCTs in South Los Angeles, California (a mixed Black and Latino community) in 2006 and 2008 found that door-to-door canvassing by members of the local organization Strategic Concepts in Organizing and Policy Education (SCOPE) were effective at increasing Black voter turnout. Black South LA voters were particularly likely to be mobilized when contacted by a Black canvasser and when contacted by a canvasser from their local community (García Bedolla and Michelson 2012; Michelson and García Bedolla 2015; Sinclair et al. 2013).

The power of these face-to-face interactions supports García Bedolla and Michelson's Theory of Sociocultural Cognition regarding the power of personalized outreach to lowpropensity voters, and also theories about the power of shared Black consciousness. Black voters are uniquely influenced to be loyal to the Democratic Party and to participate in elections due to well-understood behavioral norms with roots in Black liberation politics (White and Laird 2020). Reinforcing Dawson's theory of Black linked fate, White and Laird argue that the roots of Black political unity were established through the adversities of slavery and segregation, when Black Americans forged uniquely strong social bonds for survival and resistance. These tight communities have continued to produce and enforce political norms including Democratic Party identification in the post-Civil Rights era. The social experience of race for Black Americans is 
thus fundamental to their political choices. Black voters are uniquely influenced by the social expectations of other Black Americans to prioritize the group's ongoing struggle for freedom and equality. When navigating the choice of supporting a political party, this social expectation translates into affiliation with the Democratic Party. ${ }^{1}$

Black voter turnout does not necessarily follow rules about political participation developed from studies of white Americans (Philpot, Shaw, and McGowen 2009). Summarizing pathbreaking work by Dawson (1994), Harris (1999) and McDaniel (2008), Tasha Philpot and her coauthors note: "Unlike other groups in society, indigenous institutions that surfaced out of Blacks' unique history play as important a role in determining Black's motivation to engage in politics as do individual-level characteristics or other group attachments such as party identification" (2009, p. 999). Harris (1999) documents the example of Black clergy mobilizing their members during the Civil Rights Movement, and also that Black parishioners overwhelmingly support church-based political activism. McDaniel (2008, p. 19) notes that Black church-based activism reflects the relative lack of other resources among Black Americans, including few Black elected officials at the federal level, few and less-well funded interest organizations that represent the African American community, even fewer Black political action committees, and ongoing registration and voting restrictions that systematically disenfranchise eligible Black voters.

The very limited number of published RCTs examining Black GOTV efforts does not reflect the high level of mobilization activity regularly delivered by Black-serving organizations, including churches. Laird and White note that Black voters in Alabama delivered the margin of

\footnotetext{
${ }^{1}$ These same social pressures make Black Americans more likely to overreport their voting behavior compared to other Americans (Cassel 2019); this emphasizes the importance of basing conclusions about how to best get out the vote among Black Americans on studies using validated voter turnout data, as we do here.
} 
victory for Doug Jones in his bid for the U.S. Senate in a special election in December 2017. Although $60 \%$ of Black voters were unaware of the scheduled election just a few weeks earlier, high Black turnout (and near-unanimous support for Jones) gave Democrats a victory. This turnout was fueled "by relentless on-the-ground mobilization efforts of black organizations and black social networks" (2020, p. 2).

\section{The 2020 Pandemic and Vote-by-Mail}

Among the many ways that the COVID-19 pandemic upended life in the United States in 2020 was a disruption of usual methods of mobilizing voters to participate in elections. Just as millions of voters were being asked to cast their ballots in primaries and caucuses, and later for the November elections, they were also asked to shelter indoors and practice social distancing. Community organizations with plans to engage in door-to-door canvassing and other best practices for increasing voter turnout had to innovate with new, pandemic-safe methods of registering and mobilizing eligible voters. One notable innovation came from Black Girls Vote, Inc., a non-partisan community organization based in Baltimore. Their pilot project, Party at the Mailbox (PATM), sought to increase vote-by-mail participation in the June 2 primary. Reflecting the decrease in African American turnout in 2016 compared to the previous two presidential elections, the project also sought specifically to shift attitudes and identities - to create a greater sense of identity as a voter and to generate feelings of shared community.

We conducted a multi-method evaluation of the PATM pilot, using a randomized controlled trial, an Internet survey, one-on-one interviews with registered voters and community leaders, and focus groups. We documented significant shifts in attitudes and behavior, including a double-digit increase in voter turnout among low-propensity voters who shared a household with someone who participated in the project. Building on those results, we expanded to three 
cities for the November 3 elections, adding Detroit, Michigan and Philadelphia, Pennsylvania. In late 2021, we launched a fifth effort in the Atlanta, Georgia metropolitan area, for the U.S. Senate runoff elections on January 5, 2021; while we lack RCT data for that final iteration, we do have survey, interview, and focus group data. In this paper, we share details and preliminary results from all of those iterations of PATM.

\section{Get-Out-the-Vote Research}

There is a rich literature on the most effective ways to get out the vote, both generally and when specifically targeting low-propensity communities of color. These range from traditional methods including door-to-door canvassing, phone banking, and mail, to newer tactics including text messages and relational organizing. The tactic on which PATM was modeled is Party at the Polls (Addonizio, Green, and Glaser 2007). As Addonizio et al. note, modern elections lack the festive atmosphere of the $19^{\text {th }}$ century; these modern Election Festivals were designed to generate a similarly celebratory atmosphere and thus increase voter turnout.

The original study, including two pilot projects in 2005 and another 12 RCTs in 2006, generated an estimated effect of 2.5 percentage points $(\mathrm{SE}=1.2)$. The racial makeup of the 14 test sites varies, but none are majority-Black and most are majority-Anglo (non-Latino white). All 14 elections were low- to medium salience, ranging from a municipal race where no candidates faced challengers to contested midterm federal elections. Several rounds of additional experiments have been conducted by Donald Green and Oliver McClellan, with mixed results. Green and McClellan examine eight election festival RCTs conducted for the 2016 general election. In this high-salience context, they find an average estimated effect of 3.8 percentage points $(\mathrm{SE}=1.6)$. Estimated effects of further follow-up experiments with a much larger set of festivals are weaker: over 100 festivals were conducted across multiple sites in 2017 and 2018, 
with no measurable effect on turnout. Green and McClellan posit that this may be due to the widespread rain on that day, which likely influenced festival attendance. Looking at a smaller number of early vote festivals conducted in $2018(\mathrm{~N}=7)$ they find an effect of 3.5 percentage points $(\mathrm{SE}=1.2)$. Overall, they conclude that election festivals are an effective and cost-effective means for increasing voter turnout, with a pooled estimate including all studies from 2005 through 2018 of 1.6 percentage points ( $\mathrm{SE}=0.81)($ Green and McClellan 2017, 2020).

The small effects for the large number of festivals conducted in 2017 and 2018 sit in stark contrast to the consistently strong effects found in the earlier RCTs and in the 2016 general election. Overall, we interpret these results as suggesting that the tactic of making a voting a celebratory community event is effective across elections of low, medium, and high salience but that the focus on single-day events leaves the tactic vulnerable to unanticipated weather events or other disruptions. PATM avoids this potential disruption of GOTV efforts because the celebration takes place over time, allowing for word to spread, for excitement to build, and, as an additional unanticipated benefit, for flexibility in the face of weather-related or other disruptions.

The power of a celebratory, community-based effort to raise turnout among lowpropensity voters also builds on scholarship about the power of linked fate and group identity, and also on the power of emotions. PATM engaged with registered voters in these communities as members of strongly-felt ingroups, e.g., as Black women. This combination of primed ingroup identity and group norms with positive emotions generated strong effects on voter turnout, while also building community and positive affect among participating voters.

Another GOTV tactic related to PATM is the idea of encouraging turnout by eligible voters using gifts, as the project gave households a box of desirable goods. The use of cash or other incentives to motivate voter turnout and vote choice is widespread in the developing world, 
where clientelistic goods are not illegal; multiple studies document their pervasiveness and effectiveness at increasing turnout (Vicente 2014; Murugesan 2020). Specific material advantages, including access to public services, jobs, cash, and gifts, are used in democracies in countries in the Americas, Africa, Asia, and the Middle East to deliver material advantages to political supporters (Murugesan 2020). While in some instances this takes the form of vote buying, in other instances where individual votes cannot be monitored (where there is a secret ballot) politicians and political parties reward supporters for showing up at the polls, which Nichter (2008) differentiates as "turnout buying." In the United States, where compensating individuals for voting is a violation of federal law, there are nevertheless strong traditions in many communities of building relationships with voters through the use of incentives. In Street Fight, the 2005 movie chronicling the 2002 Newark, New Jersey mayoral race between incumbent Sharpe James and Cory Booker, both candidates ply voters with gifts and food, including flowers and perfume, potholders, chartered buses to Atlantic City, and tickets to concerts and the circus.

Academic efforts to encourage turnout with actual cash has met with mixed results. Costas Panagopoulos conducted two GOTV experiments offering cash payments for participation in local California elections in 2007 and 2010 (thus eluding federal bans on paying citizens to vote); his results suggest that non-nominal payments are more effective than simple reminders at increasing turnout (Panagopoulos 2013). Victoria Shineman conducted a "supertreatment" GOTV experiment in a local California election in 2011, combining cash payments with information about how to register and vote and multiple emailed reminders about the election, generating a large increase in turnout as well as statistically significant increases in political knowledge (Shineman 2018). 
In summary, in addition to motivating turnout as a celebration of community, PATM may also increase turnout by creating a clientelistic relationship with voters, nudging them to participate to reciprocate the box that they received. Note that this was never messaged to the voters, and that PATM staff were careful to never imply that they were requiring a promise of turnout in return for participation in the program or acceptance of a box delivery.

\section{The Baltimore Pilot}

Black Girls Vote (BGV) initially sought to mirror the festive atmosphere of election festivals to build community and participation in the June 2020 primary in Baltimore. The intervention was a hand-delivered cardboard box designed to encourage recipients to celebrate vote-by-mail participation in their own homes. Several organizations like Stand Up Baltimore and Just Our Youth Group worked in partnership by offering their physical space to assemble and store the boxes. The anchor organizational partner was Baltimore Votes, a non-partisan community group working to increase voter turnout in the city. According to Baltimore Votes Co-founder Sam Novey, ${ }^{2}$ Baltimore Votes provided support for PATM in multiple ways:

We shifted our budget from Parties at the Polls to support the Party at the Mailbox pilot, raised emergency funds to support the evaluation, and deployed our communications team and email list to promote the campaign. We also mobilized our past Parties at the Polls partners and board members to promote the campaign in their communities and host community activations like car parades and voter education events.

Support from Baltimore Votes provided key institutional and financial support for the Party at the Mailbox idea pitched by BGV. This included contacting academic researchers interested in structuring the effort so as to allow for a robust test of its effectiveness, which led to the research team that authored this paper.

\footnotetext{
${ }^{2}$ Personal communication, 9/10/21
} 
The Baltimore pilot box included informational materials on voting but also festive items including a t-shirt, balloons, posters, local snacks like Berger Cookies, and a coloring book with crayons. The PATM materials intentionally incorporated Black-centered engagement materials that made a nod to voting as a community celebration and collective effort. For example, the font used for the posters in the PATM box was a traditional font used by Black jazz bands. The Black Girls Vote posters deliberately excluded the election date to signal that the community celebration should extend beyond election day and that civic engagement is a year-long endeavor.

The boxes were hand-delivered (in a pandemic-safe way), adding a human interaction to the outreach. Participants were recruited via social media, local news media, and in partnership with local, trusted community organizations. In addition, social influencers were given boxes and asked to share about them to their networks. Individuals interested in receiving their own box were directed to sign up via a Google form on the program's main website.

After the organizations removed the individuals who were given boxes initially (such as social influencers and people assisting in our outreach efforts), the interest lists were sent to the authors. The lists were cleaned, and then individual records were matched to their data in the City of Baltimore voter file, then randomized by the authors into treatment and control groups. Each day, the community organizations told the authors how many boxes were on track to be delivered, their delivery capacity, and if there were any undeliverable boxes. This allowed the evaluation team to support PATM efforts by adjusting the lists and pulling more names when necessary. The deliveries stopped June $1^{\text {st }}$ (the day before the election).

Individuals who signed up (regardless of their assignment to treatment or control) were also invited to on- and off-line activities including a car caravan and an Election Night music 
party on Facebook, which generated 10,000 views. For the parade, voters decorated their cars with PATM signs and made their way through the city accompanied by amplified music and verbal messages from BGV founder and president Nykidra Robinson and other local leaders; over 40 cars were part of the caravan. As Robinson likes to say, "it's not just a box, it's an experience." With local treats and artwork, each box was a true representation of the community. The posters and other printed items were decorated with iconic graphics from the Globe Collection and Press at MICA (the Maryland Institute College of Art). Globe's signature style of bold letterpress wood type with a distinctive distressed patina on top of Day-Glo backgrounds is immediately recognizable by Baltimore residents. Globe resonates as a long-time local print shop that has produced graphics supporting local and national Black artists and entertainers dating as far back as the 1930s as well as modern political movements including Black Lives Matter.

The boxes were delivered by hand. Local community organizations were given subgrants to promote the program while supporting local residents (e.g., food giveaways); overall, PATM partnered with 60 local community organizations for the pilot effort. Fostering community spirit was deeply embedded in the campaign. These efforts were echoed by voters who felt the box was a celebration of their city and their excitement to vote for a better future. As boxes began to be delivered (and unboxed in Instagram videos), excitement grew. Participants posted celebratory photos on social media. The campaign generated significant local and national media attention and coverage. Locally, PATM was featured on the front page of the Baltimore Sun newspaper and also highlighted by WBAL (the local NBC affiliate); nationally, PATM was featured in news outlets including Forbes magazine, MSNBC's The ReidOut with Joy Reid, and in USA Today. Guests at the Election Night PATM virtual dance party included the Rev. Jesse Jackson, Jr. and the president of the Maryland State Senate. 
Baltimore Votes, a local voter advocacy organization focused on local voter turnout, played a distinct and vital role in raising local awareness of PATM. Baltimore Votes cooperated with BGV in 2018 to host an election festival in Baltimore and thus had a strong community presence and a base of trust coming into 2020. The two organizations (Baltimore Votes and Black Girls Vote) worked closely together to organize and execute the PATM pilot (and the subsequent replications).

Overall, we 3,390 people registered for a chance to receive a PATM box before the Baltimore primary election, providing their full name, address, and birth year. From this information, we were able to match 1,098 individuals from the interest lists to their voting record; 680 were randomly assigned to the treatment group and 418 to the control group. Our analysis examines turnout and behavior of these 1,098 party "hosts" as well as their 2,018 party "guests" (household members who are registered voters), including 1,189 in treatment households and 829 in control households.

Results from the pilot were enormously encouraging, as shown in Table 1. We estimate that turnout increased by 2.5 percentage points among members of treatment group households, compared to the treatment group. We looked separately for effects among high- and lowpropensity voters, defining high-propensity voters as those with a 50\% or higher likelihood of participating. ${ }^{3}$ Individuals who signed up to receive a PATM delivery (our party "hosts") tended to be high-propensity voters and very likely to vote in the June primary regardless of whether they were assigned to treatment. Turnout for these voters was $87.3 \%$ in the control group and

\footnotetext{
${ }^{3}$ Voter propensity scores were provided by Catalyst for the Baltimore pilot but were calculated with voter histories and demographic variables provided in local voter files for the follow-up RCTs (for methodology see Barber et al. 2014). We categorize participants into two groups based on these scoreslow propensity ( $<50 \%$ likely) and high propensity ( $\geq 50 \%$ likely) voters.
} 
$88.9 \%$ in the treatment. There is also no measurable difference among household members (party "guests") when examining individuals at all levels of vote propensity. Lower-propensity party guests, however, were far more likely to participate if they "attended" a household party. Here, turnout increases from $19.0 \%$ in the control group to $31.3 \%$ in the treatment group, a statistically significant effect of 12.3 percentage points $(p=0.00) .{ }^{4}$ As shown in Figure 1 , the effect of attending a PATM party increases among guests as vote propensity decreases.

Table 1. Party at the Mailbox: Baltimore Primary 2020 Pilot RCT

\begin{tabular}{|c|c|c|c|c|}
\hline & $\mathrm{N}$ & $\begin{array}{c}\text { Control Turnout } \\
(\%)\end{array}$ & $\begin{array}{c}\text { Treatment } \\
\text { Turnout }(\%)\end{array}$ & Difference \\
\hline Everyone & 3,116 & 57.2 & 59.7 & $2.5^{*}$ \\
\hline Low-Propensity Voters & 277 & 19.0 & 31.4 & $12.4^{*}$ \\
\hline High-Propensity Voters & 1,839 & 85.7 & 84.1 & -1.6 \\
\hline Hosts & 1,098 & 89.0 & 87.4 & -1.6 \\
\hline High-Propensity Hosts & 1,052 & 91.3 & 89.5 & -1.8 \\
\hline Low-Propensity Hosts & 46 & 31.3 & 40.0 & 8.7 \\
\hline Guests & 2,018 & 41.1 & 43.8 & 2.7 \\
\hline High-Propensity Guests & 787 & 78.7 & 76.5 & -2.2 \\
\hline Low-Propensity Guests & 231 & 16.9 & 29.6 & $12.7^{*}$ \\
\hline
\end{tabular}

Note: Asterisks indicate differences that are statistically significant $(p<.05$, one-tailed). Our analysis includes all household members, not just the individuals who signed up to participate. This increases our sample size from $1,098(1,869$ in treatment $+1,247$ in control $)$ to 3,116 .

\footnotetext{
${ }^{4}$ All p-values are one-tailed.
} 
Figure 1. 2020 Baltimore Pilot, Effect of Assignment to Treatment on Guest Turnout, by Vote Propensity

\section{Effect of the Treatment}

Among Low \& High Propensity Voters

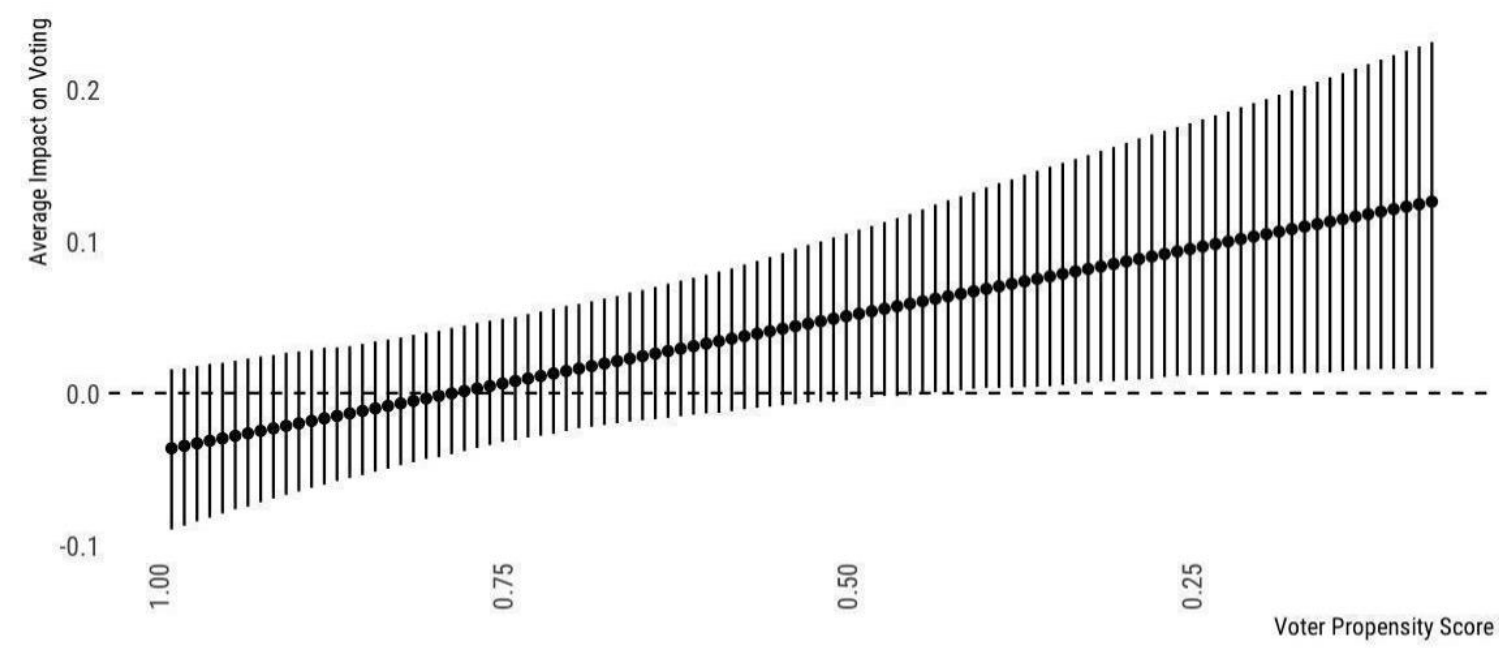

Party at the Mailbox 2020

\section{Post-Election Survey Data}

After the election, we analyzed the effect of assignment to treatment in multiple ways, including comparison of validated voter turnout in the treatment and control groups, an on-line survey, one-on-one telephone interviews (with registered voters and community leaders), and Zoom focus groups. We hypothesized that assignment to treatment would increase turnout and feelings of community identity and political efficacy.

Immediately following the election, individuals who signed up to receive a box (including individuals randomly assigned to both the treatment and control group) were invited via email to complete a Qualtrics survey (see Appendix for survey instrument). The invitation came from a member of our academic team, using a Black Girls Vote email address. Participants were thanked for their time with a $\$ 10$ Amazon gift card. The survey was in the field from June 
22 to July 7, 2020. A total of 480 usable surveys were completed; $70 \%$ of participants were from a household that received a box, and 30\% from households in the control group. Respondent age ranged from 18 to $76($ mean $=42.3)$; most $(88 \%)$ respondents identified as female, $11 \%$ as male, and three as non-binary. Most $(64 \%, \mathrm{~N}=306)$ identified as Black or as multiple races including Black, another large proportion identified as white, non-Hispanic (29\%, N=139), and the remaining 35 respondents (7\%) identified as Asian only, Hispanic only, Middle-Eastern or Arab, mixed race not including Black, or other. Of those providing a partisan identification, most (92\%) identified as Democrats (including leaners). Reported turnout was very high among these survey respondents, consistent with the high turnout rates among party hosts found in the RCT. Among control group hosts, turnout was reported at 93.6\%; among treatment group hosts, at 96.4\%; the difference of 3.0 percentage points is not statistically significant.

While our survey found negligible differences in reported turnout, we did find evidence that participation in the program (having a box delivered to the household) did affect political attitudes. Individuals assigned to the treatment group were more likely than individuals in control households to report stronger identities as Baltimoreans, as shown in Table 2. The total effect of the treatment compared to the control is a 0.197-point increase in identity as a Baltimorean $(p<$ 0.05). The effect persists when we control for gender, education, race, and years lived in Baltimore $(b=0.13, p<0.05)$.

Table 2. Identity as a Baltimorean, by Treatment Group, 2020 PATM Pilot (percentages)

\begin{tabular}{|l|c|c|}
\hline & Control $(\mathrm{N}=141)$ & Treatment $(\mathrm{N}=339)$ \\
\hline Not at all & $4.26 \%$ & $3.54 \%$ \\
\hline Not very well & 18.44 & 10.32 \\
\hline Very well & 41.13 & 37.76 \\
\hline Extremely well & 36.17 & 43.38 \\
\hline
\end{tabular}

Question wording: "How well does the term Baltimorean describe you?" Coded 0=not at all to 3=extremely well. Data collected June 22 to July 7, 2020. 
We also asked survey participants a series of questions meant to measure political efficacy. The first question read, "When it comes to election policy, how much confidence, if any, do you have in each of the following parts of government to act in the best interest of the public?" Hosts in the treatment group consistently rated all levels of government (federal government, Maryland state legislature, governor of Maryland, Maryland state Board of Elections, City of Baltimore Board of Elections, and state elections officials) more positively than hosts in the control group. However, only differences in attitudes about the federal government reached statistical significance $(b=0.28, p<0.00)$. When all levels of government are treated as a scale, the effect of the treatment is positive and approaching statistical significance $(b=0.03 ; p=0.05)$. Similarly, hosts in the treatment group tended to report slightly higher levels of political efficacy in response to other survey items, but the differences do not reach statistical significance.

\section{General Election Efforts}

Overall, the PATM pilot exceeded expectations in terms of both attitudinal and behavioral effects. Buoyed by this success, Black Girls Vote moved to expand the project to additional cities for the general election and beyond. Funds and community partnerships were secured to replicate in Baltimore and to expand to two additional cities for the November 3, 2020 election: Detroit and Philadelphia. In addition, PATM was conducted in the Atlanta, Georgia metropolitan area for the January 2021 U.S. Senate runoff election. The randomization procedure and analysis plans for the three November election efforts mirrored those from the June pilot; as noted above, we are unable to provide an RCT analysis for Atlanta due to a lack of appropriate data. These follow-up efforts allowed us to explore additional hypotheses, including the effect of randomizing the source of the invitation to participate in the survey and differences in election 
salience and geographic context. After the November 2020 and January 2021 elections, we collected survey, interview, and focus group data as with the pilot, but with some nuances as noted below.

The follow-up efforts in November 2020 differed from the pilot in additional small ways. Delivery was still made by local partners, but now in a van wrapped with PATM graphics and information. Social media presence of the campaign also ramped up. During one day of the campaign, Lady Gaga allowed Nykidra Robinson to take over her Instagram feed to promote the PATM project. Local publicity in Detroit was also provided by the NBA's Detroit Pistons and local apparel company Detroit vs. Everybody. The project was again covered by local and national media, including WXYZ television, the ABC affiliate in Detroit, and Philadelphia Magazine.

Baltimore, November 2020

For the general election in Baltimore, we expanded from the pilot to include a larger number of boxes and a larger geographic area: Baltimore County in addition to Baltimore City (Baltimore City and Baltimore County are independent jurisdictions and do not overlap). While generally mirroring the pilot, the general election effort in Baltimore included a slightly different box of goodies including Herr's Old Bay chips, an Under Armour mask, local spices, Otterbein's cookies, locally made hand sanitizer, and more; also, boxes were delivered in a van wrapped with PATM graphics and information. Boxes were delivered October 21-30. The RCT included 1,460 boxes and 2,204 individuals ( 848 hosts and 1,356 guests). We hypothesized that the effect of our treatment would be smaller given the increased salience of a general presidential election, and that, as in the pilot, the effect would be isolated to low-propensity party guests. Results support these hypotheses, as shown in Table 3. 
Among party hosts, turnout is not affected by assignment to the treatment condition:

turnout is $92.5 \%$ among those in the control condition and $93.93 \%$ among those in the treatment condition; the difference of 1.5 percentage points is negligible and not statistically significant. In contrast, assignment to treatment increases turnout among low-propensity party guests by an estimated 5.2 percentage points, from $52.6 \%$ in the control group to $57.8 \%$ in the treatment group $(p=0.09)$. Looking at voter turnout for all low-propensity participants (including both guests and hosts), the effect is a statistically significant increase of 5.3 percentage points ( $p=$ 0.05), but there is no measurable difference among low-propensity hosts.

Table 3. Party at the Mailbox: 2020 Baltimore General Election RCT

\begin{tabular}{|l|c|c|c|c|}
\hline & $\mathrm{N}$ & $\begin{array}{c}\text { Control Turnout } \\
(\%)\end{array}$ & $\begin{array}{c}\text { Treatment } \\
\text { Turnout }(\%)\end{array}$ & Difference \\
\hline Everyone & 2,204 & 78.9 & 79.8 & 0.9 \\
\hline Low-Propensity Voters & 866 & 58.4 & 63.7 & $5.3^{*}$ \\
\hline High-Propensity Voters & 1,338 & 91.7 & 90.4 & -1.3 \\
\hline Hosts & 848 & 92.5 & 94.0 & 1.5 \\
\hline High-Propensity Hosts & 655 & 96.6 & 97.0 & 0.4 \\
\hline Low-Propensity Hosts & 193 & 78.4 & 83.9 & 5.5 \\
\hline Guests & 1,356 & 70.3 & 71.0 & 0.7 \\
\hline High-Propensity Guests & 683 & 87.1 & 84.2 & -2.9 \\
\hline Low-Propensity Guests & 673 & 52.7 & 57.9 & $5.2^{*}$ \\
\hline
\end{tabular}

Note: Asterisks indicate differences that are statistically significant (one-tailed). Our analysis includes all household members, not just the individuals who signed up to participate. This increases our sample size from $848(1,337$ in treatment $+2,204$ in control) to 2,204.

After the election, we again invited hosts to complete a survey in exchange for a $\$ 10$ Amazon gift card. In contrast to the pilot election, and perhaps reflecting the context (the postelection controversy over the results and the holiday season), response rates were slower and smaller. Overall, we collected 292 usable surveys between November 10 - December 7, 2020; $66 \%$ of hosts were from the treatment group, and $33 \%$ from the control group. In contrast to the results from the Baltimore pilot effort, this post-election survey data from November found no 
statistically detectable differences in political identification or political efficacy between individuals in the treatment and control groups (see Appendix for details).

\section{Detroit and Philadelphia 2020}

In addition to replicating PATM in Baltimore, in November 2020 BGV and their partners expanded to battleground cities with high proportions of Black voters. In Detroit, PATM partnered with 40 community organizations to distribute 2,000 boxes, 531 of which were part of the RCT. Overall, the Detroit RCT includes 531 hosts assigned to treatment and 457 assigned to the control group ( $\mathrm{n}=988$ ). Adding household members increases the size of the overall Detroit RCT to 2,340. Boxes were delivered October 23-31. In addition to the voting information materials, the Detroit box had a Detroit Pistons baseball cap and local goodies including Better Made BBQ chips, a Faygo pop, and a Sander's chocolate bar shaped as Michigan's lower peninsula . In Philadelphia, PATM partnered with 60 community organizations to distribute 5,150 boxes, including 2,209 households in the treatment group. The control group included 1,599 households. Overall, there were 9,447 individuals in the Philadelphia RCT. Boxes were delivered October 22 - November 1. The Philadelphia boxes included local treats including Tastykake Butterscotch Krimpets, Utz potato chips, and Peanut Chews. All November boxes also included an Under Armour mask.

Given the very high electoral salience of battleground cities in battleground states for a presidential election, we were skeptical that we would detect measurable differences in turnout in Detroit or Philadelphia. As expected, there are no statistically significant difference in turnout between the treatment and control groups, even among low-propensity party guests (see Tables 4 and 5). In these cities, rates of turnout even for low propensity voters were extremely high, leaving fewer individuals on the cusp of participation for mobilization. 
After the election, we collected 255 surveys in Detroit and 558 surveys in Philadelphia, using the same method as in Baltimore. Participation was low and relatively slow in both Detroit (November 11 - December 5, 2020) and Philadelphia (November 11 - December 6, 2020), possibly due to the post-election context of battles over the vote results. Participants in each city included an equal mix of treatment and control hosts. In both cities, we fail to find statistically significant differences in reported identities or feelings of political efficacy (see Appendix for details).

Table 4. Party at the Mailbox: Detroit November 2020 RCT

\begin{tabular}{|l|c|c|c|c|}
\hline & $\mathrm{N}$ & $\begin{array}{c}\text { Control Turnout } \\
(\%)\end{array}$ & $\begin{array}{c}\text { Treatment } \\
\text { Turnout }(\%)\end{array}$ & Difference \\
\hline Everyone & 2,340 & 81.0 & 78.2 & -2.8 \\
\hline Low-Propensity Voters & 1,234 & 77.0 & 75.7 & -1.3 \\
\hline High-Propensity Voters & 1,106 & 85.1 & 81.0 & -4.1 \\
\hline Hosts & 988 & 82.9 & 81.4 & -1.7 \\
\hline High-Propensity Hosts & 537 & 83.7 & 80.1 & -3.5 \\
\hline Low-Propensity Hosts & 451 & 82.1 & 82.8 & 0.8 \\
\hline Guests & 1,352 & 79.4 & 75.9 & -3.5 \\
\hline High-Propensity Guests & 783 & 86.4 & 81.9 & -4.5 \\
\hline Low-Propensity Guests & 569 & 73.6 & 72.0 & -1.6 \\
\hline
\end{tabular}

Note: None of the differences shown here are statistically significant. Our analysis includes all household members, not just the individuals who signed up to participate. This increases our sample size from 988 $(1,300$ in treatment $+1,040$ in control) to 2,340 .

Table 5. Party at the Mailbox: Philadelphia November 2020 RCT

\begin{tabular}{|l|c|c|c|c|}
\hline & $\mathrm{N}$ & $\begin{array}{c}\text { Control Turnout } \\
(\%)\end{array}$ & $\begin{array}{c}\text { Treatment } \\
\text { Turnout }(\%)\end{array}$ & Difference \\
\hline Everyone & 9,447 & 79.5 & 75.2 & -4.3 \\
\hline Low-Propensity Voters & 2,956 & 60.3 & 57.3 & -3.1 \\
\hline High-Propensity Voters & 6,491 & 87.2 & 84.0 & -3.2 \\
\hline Hosts & 3,808 & 91.1 & 91.3 & 0.2 \\
\hline High-Propensity Hosts & 3,147 & 93.5 & 93.3 & -0.3 \\
\hline Low-Propensity Hosts & 661 & 78.7 & 82.0 & 3.3 \\
\hline Guests & 5,639 & 71.3 & 64.7 & -6.6 \\
\hline High-Propensity Guests & 3,344 & 81.3 & 75.3 & -6.0 \\
\hline Low-Propensity Guests & 2,295 & 54.6 & 50.6 & -4.0 \\
\hline
\end{tabular}

Note: Our analysis includes all household members, not just the individuals who signed up to participate. This increases our sample size from 3,808 (5,592 in treatment $+3,855$ in control) to 9,447. 
Atlanta 2021

In addition to the November 2020 RCTs, we conducted a Party at the Mailbox effort in the Atlanta, Georgia metropolitan area in the weeks leading up to the January 5, 2021 U.S. Senate runoff elections. Because reliable records about box signups and distribution are not available, we cannot conduct an RCT analysis. However, we do share results from the postelection surveys, interviews, and focus groups, where we have confidence about whether individuals were from treatment or control households. Building on results from earlier rounds where we found effects centered on party guests rather than hosts, our post-election survey in Atlanta was amended to allow party hosts who completed the survey to share a survey link with a household member. This was intended to include party guests in our survey data.

Overall, we collected 596 surveys (513 hosts and 83 guests) between January 19 and February 8,$2021 ; 54 \%$ of participants were from a household that received a box, and $45 \%$ from households in the control group. Guests were also invited to participate in focus groups. Respondent age ranged from 18 to $79($ mean $=37.6)$; most $(84 \%)$ respondents identified as female, $14 \%$ as male, one as non-binary, and one as a transgender female. Most $(80 \%, \mathrm{~N}=433)$ identified as Black or as multiple races including Black, another 50 identified as white, nonHispanic (9\%), and the remaining 54 respondents (9\%) identified as Asian only, Hispanic only, Middle Eastern or Arab, mixed race not including Black, or other. Of those providing a partisan identification, most (92\%) identified as Democrats (including leaners). 
Table 7. Identity Strength, Party at the Mailbox, 2021 Atlanta Survey

\begin{tabular}{|c|c|c|c|}
\hline & Control Group Average & Treatment Group Average & Difference \\
\hline \multicolumn{4}{|c|}{ Identity as an Atlantan } \\
\hline Everyone & 2.02 & 2.20 & $0.18^{*}$ \\
\hline Hosts & 2.16 & 2.20 & 0.04 \\
\hline Guests & 1.36 & 2.23 & $0.86^{*}$ \\
\hline \multicolumn{4}{|c|}{ Identity as an American } \\
\hline Everyone & 2.08 & 2.39 & $0.31 *$ \\
\hline Hosts & 2.12 & 2.38 & $0.25^{*}$ \\
\hline Guests & 1.92 & 2.53 & $0.60 *$ \\
\hline \multicolumn{4}{|c|}{ Identity as a Voter } \\
\hline Everyone & 2.53 & 2.76 & $0.23 *$ \\
\hline Hosts & 2.63 & 2.77 & $0.13^{*}$ \\
\hline Guests & 2.02 & 2.66 & $0.64 *$ \\
\hline \multicolumn{4}{|c|}{ Agree that the government in Atlanta cares what people like me think } \\
\hline Everyone & 0.60 & 0.63 & 0.03 \\
\hline Hosts & 0.62 & 0.63 & 0.00 \\
\hline Guests & 0.49 & 0.66 & $0.16^{*}$ \\
\hline \multicolumn{4}{|c|}{ Agree that people like me have a say in what the federal government does } \\
\hline Everyone & 0.65 & 0,72 & $0.06^{*}$ \\
\hline Hosts & 0.67 & 0,73 & $0.06^{*}$ \\
\hline Guests & 0.58 & 0.64 & 0.06 \\
\hline \multicolumn{4}{|c|}{ Agree that the government in Washington DC cares what people like me think } \\
\hline Everyone & 0.42 & 0.46 & $0.04 *$ \\
\hline Hosts & 0.42 & 0.47 & $0.04 *$ \\
\hline Guests & 0.41 & 0.43 & 0.02 \\
\hline
\end{tabular}

Note: Identity survey items are coded 0 (not at all) to 3 (very well). Differences noted with an asterisk are statistically significant. Efficacy items are coded on a scale from 0-1, with higher scores indicating higher levels of political efficacy Data collected January 19 - February 8, 2021.

As shown in Table 7, Atlantans randomly assigned to the treatment group-especially party "guests" - reported stronger feelings of political identification with their city $(b=0.18, p=$ $0.01)$, as voters $(b=0.23, p=0.00)$, and as Americans $(b=0.23, p=0.00)$. Treatment group participants also reported stronger feelings of political efficacy, a finding we also saw in the Baltimore pilot survey data, although not consistently across all levels of government or across both hosts and guests. 
The two successful Party at the Mailbox efforts in Baltimore, including the pilot and the larger November 2020 effort, constitute significant evidence that the method works to increase voter turnout in lower- and medium-salience elections. At the same time, the null RCT results in Detroit and Philadelphia indicate that it may not work as well in very high salience elections, or that the model may need to be changed to be effective in high-salience contexts. In general, it is difficult to document effective GOTV efforts in a presidential election. GOTV RCTs targeting majority-Black communities in November 2008 also did not find effects on turnout (García Bedolla and Michelson 2012). However, that we are unable to document shifts in voter turnout in these two instances is not necessarily incompatible with the idea that the project worked to influence hearts and minds in those cities. We used interviews with voters and organizational leaders, as well as focus group discussions, to explore how the project was received and remembered by members of the treatment and control groups in each city. These data help pinpoint the aspects of the program that resonated with voters and that are likely to be key to successful future PATM efforts. We turn now to those qualitative data.

\section{General Election Qualitative Methodology and Data}

After each RCT, we collected qualitative data via semi-structured interviews and focus group conversations, using Zoom. Participants were recruited via email sent from a Black Girls Vote email address (or a Baltimore Votes email address, for the Baltimore pilot). Invitations were distributed to individuals who had signed up to receive a box or who were representatives of a partner organization. The interview team and focus group coordinators invited batches of 10 randomly selected people from each list to participate until we met our participation goals. Each participating voter received a $\$ 50$ Amazon gift card; representatives from local partner organizations were not compensated. Overall, we spoke to 95 individual voters and 44 
organization representatives and conducted 17 focus groups that included 92 people (see Table 8). We used this qualitative data to explore how PATM was received by and affected our target communities.

Table 8. PATM Qualitative Data

\begin{tabular}{|l|c|c|c|}
\hline & $\begin{array}{c}\text { Total Interviews } \\
\text { (voters, organization } \\
\text { leaders) }\end{array}$ & $\begin{array}{c}\text { Focus Groups } \\
\text { (participants, groups) }\end{array}$ & $\begin{array}{c}\text { Dates of Data } \\
\text { Collection }\end{array}$ \\
\hline $\begin{array}{l}\text { Baltimore } \\
\text { Primary 2020 (Pilot) }\end{array}$ & $\begin{array}{c}36 \\
(22,14)\end{array}$ & 25,3 & $7 / 2 / 20-7 / 29 / 20$ \\
\hline $\begin{array}{l}\text { Baltimore } \\
\text { General 2020 }\end{array}$ & 30 & 8,2 & $12 / 8 / 20-12 / 28 / 20$ \\
\hline Detroit 2020 & $(22,8)$ & 24,5 & $12 / 18 / 20-1 / 16 / 21$ \\
\hline Philadelphia 2020 & $(12,7)$ & 11,3 & $12 / 18 / 20-1 / 18 / 21$ \\
\hline Atlanta 2021 & $(16,8)$ & 24,4 & $1 / 22 / 21-2 / 9 / 21$ \\
\hline TOTAL & $29(22,7)$ & 92,17 & $7 / 2 / 20-2 / 9 / 21$ \\
\hline
\end{tabular}

Given historical (and justified) caution in Black communities about participating in research studies (Zinn 1979), we took deliberate steps to ensure that interviewers and focus group coordinators had cultural competency and would make participants feel comfortable. Our qualitative data collection team included 15 faculty and graduate and undergraduate students from local colleges and institutions, including HBCUs. Interviewers were recruited and trained by the evaluation team prior to data collection.

The interview script and focus group guiding questions focused on how individuals viewed themselves in relation to their communities, and how they viewed PATM (see Appendix 
for scripts and demographics about the interview and focus group participants). We were broadly concerned with how PATM was perceived by participants, including whether it was seen as generating the intended feelings of community and celebration. To preview our findings, we do find these themes in the data: voters said they saw voting as a duty and that PATM helped them celebrate their pride in their communities.

Overall, we spoke to 94 individual voters and 92 focus group participants, for a total of 186 individuals. Most had lived in the city in which we spoke to them for at least 10 years with 92 participants reporting they have lived in their respective city all their life. They expressed deep ties to their neighborhoods and reported active engagement in social activities in their communities and pride in their city's culture. These relationships with their communities likely reflect the participant pool: individuals were generally hosts who had requested a PATM box, and most were high-propensity voters. Overall, 134 (72\%) of our 186 qualitative data participants were women, including 82 Black women (61\%), 6 Latinas (4\%), and 46 white women (34\%). Of our 52 male participants, 23 were Black (44\%) and 29 were White (56\%).

\section{Qualitative Data Results}

Duty, also known as the "D" term, has been used in traditional voter behavioral models since the 1960 s to explain why people still vote even when the cost may exceed the benefit (Riker and Ordeshook 1968). However, less work has examined this from a racial and gender perspective. Whereas general models cite reasons people feel a sense of duty that may arise from social norms or partisan pressures (Fieldhouse, Cutts, and Bailey 2020) interviews with members of predominantly Black communities show that duty may come from a desire to vote because of past disenfranchisement and to protect others within the community. 
Asked whether they view voting as a choice or as a duty, participants overwhelmingly viewed voting as a duty, but not always in the same way. Some felt this duty stemmed from the need to use their vote to have a voice, some as a constitutional duty that their ancestors had fought for, and some as a means of caring for and protecting their community. Voters often mentioned more than one of these perspectives; they are not mutually exclusive.

Many noted that their sense of duty stems from a history of disenfranchisement. They acknowledged that voting rights access for marginalized communities has not always been granted, therefore they feel a responsibility to continue to vote. They said that they have a duty to vote to fulfill what others have fought for, and that it is their constitutional right. For example, a young Black woman from Baltimore who is also a member of the Alpha Kappa Alpha sorority explained that she sees voting as a duty because of the history of voter disenfranchisement among Black women in America:

As a Black woman in America, I wholeheartedly understand what it means to not have the right to vote, because in terms of my racial classifications we were considered one of the last groups of people that were able to vote even though people who look like me fought for access to voting rights before the 1940s. So, I think I'm a super voter, I've voted in every election I was eligible for. And while I take my entire family, when I became a registered voter, everyone else in my family became a registered voter because, you know, it is a fundamental right. It's a duty actually.

This voter's sense of duty is tied to the historical fight for voting access and a belief that not voting is a betrayal not only to those who waged that fight but also to her racial group.

Secondly, voters said that when they vote they are expressing their political voice as a means of generating change. Participants expressed little hope of being heard by the federal government but were more hopeful about their vote having an impact on state and especially on local officials, who are closer in proximity. 
Participants also expressed a deep sense of duty to their communities, and said that voting is a way to take care of those communities. In their interviews, voters highlighted political and economic missteps by federal and local political leaders and a view of voting as a method of harm reduction for those in their community. A Detroit mother of two linked voting as a duty to the past and to taking care of future generations:

I feel like it's your duty. I probably think of it both as a duty because our people couldn't always as a woman, or as a Black person, we could not wait. And it's a duty because what I choose affects future generations, it affects my children, it's gonna affect their children. So, it's a duty. Yeah, I think it's more of a duty than a choice, I have no choice but to vote. So, it's more of a duty for me.

Voters often expressed their sense of an overall duty to vote, but this duty was not consistently defined. Some felt a sense of duty to their communities and to the general welfare of their neighborhoods, some to the historic Black fight for suffrage, and some to their individual need to have a voice. PATM aimed to generate feelings of celebration in civic participation and emphasized in its messaging that the party they were promoting was rooted in community care. That voting was a way for local residents to celebrate their community. Comments shared with us by voters indicate that they internalized the PATM messaging as reminders of their preexisting sense of duty to their communities.

Interview and focus group participants were asked about their experience participating in PATM. For treatment group hosts, this included direct experience with the box, but even control group hosts had experiences to share, including participation in online events (e.g., the election night dance parties hosted by Black Girls Vote) and via social media. One theme that emerged was that the box made PATM participants feel like they were part of a larger collective effort, and also that the local themes of the boxes made the experience feel local to their own city. A 35year-old Black woman in Philadelphia shared her overall experience with the PATM program. 
I just thought it was great. It just really began with the way people received the boxes, how excited they were. They were like, wait, really, they're not going to spam me and we're like, no. Let's do this together. Let's eat some chips and have some fun, watch a party later or whatever. So, it was just the energy of having these boxes. It was cool to be a part of that, really was, and then to hear people be like, I really got a box. It said it was happening in other cities. But it also felt very local. Same time, you know, it felt very local because you had those local items there like the Tastykake. I just thought it was just some good energy amongst all this muck that was happening, you know, and seeing people's spirits relax and be like, oh, we're gonna get registered to vote.

This comment illustrated the effectiveness of the program in cultivating a shared community spirit of celebration about voting. This voter felt that she was part of something bigger than even her own community, because she knew PATM was also going on in other cities, but also felt that it was a local effort. It was a positive experience for her not just because of the fun items in the box but because of the connection and collective spirit it engendered.

We heard similar comments from other voters, including one Afro-Latina who has lived in Baltimore for over 10 years and received a box for the pilot but not for the general election (despite requesting a second box).

So, I participated in a party at the mailbox for the primary and then I requested for this general election, but I didn't get a kit, which is fine. I think that overall, it was an awesome initiative. I think it added some positivity and like hope, to the general feel of elections and whatnot. So, I loved when I got it, you know, putting it up in my mailbox with the balloons and taking pictures, and my kids loved the coloring book that was supplied by the Party at the Mailbox. And the t-shirt, and I mean, just like, everything was so cool. Like the Berger cookies just felt like, wow, like celebration, like I'm a part of something bigger, too. It's not just this like this one person. But like, there's all these other people that are getting this and experiencing this. And we're liking this experience as a collective. And that was pretty awesome. Powerful.

For this voter, the celebration was local, but also something bigger_-"a collective," echoing the quote above from our Philadelphia voter. That this voter was interested in participating in both 
Baltimore elections also is evidence of the positive reception that the program had among local residents.

The message about voting as a means of coming together as a community resonated with participants. They said that the box served as a reminder that voting is a community effort. In the midst of the pandemic, many individuals were not able to participate in traditional political engagement events. PATM provided a space to continue to connect with others. PATM generated not only excitement about voting, but also excitement about sharing an experience.

Participants also noted that the box served as a catalyst for conversations about voting with others, either through verbal communication with members of their households or by sharing the contents of the box, or via social media. For example, an older Black woman voter from Baltimore discussed sharing the box with her young adult daughter and her community.

My daughter was here from California for the election. So, she and I went to vote together that morning. And we took our little horns and balloons and we stood in line... and socialized. So that was about it. And I enjoyed my little treats. My daughter and I shared the peanuts. I thought that was a really nice gesture. And the T-shirt is too small for me. So, I said, I'll give it to somebody else.

Black Girls Votes encouraged social media engagement as a part of the PATM experience and our interview and focus group participants reported positive experiences engaging their networks about it in a way that cultivated a celebratory approach to voting. Box materials also cultivated face-to-face (offline) celebrations of voting. For example, a Baltimore mother discussed her 3year-old daughter interacting with the box:

\section{KS [Facilitator]}

So how did you like to participate with everything that was in the box? Did you put anything in your mailbox? Did you post anything on social media?

\section{KD}

Yeah, I did. Um, because I have a three-year-old daughter. So even though she's obviously far away from getting into anything political, I was just making sure 
that she knows that, you know, you need to vote, whether it's political or whether it's you deciding on if you want a green or purple crayon, you need to vote and always have a voice in what you want. So, I was just making, you know, making sure that I posted the Baltimore votes on the refrigerator. She saw me wearing the t-shirt. It came with some cookies in there. So, she ate the cookie.

To further drive the message that civic engagement was a collective activity, PATM boxes included engaging materials for children such as coloring pages and stickers. Placing children's items was intentional and was informed by the unique complexity of Black Americans' political socialization. Another way in which the box materials generated a community-wide celebration was the sharing of posters and balloons in spaces visible to the public, i.e., in car and home windows, on sidewalk mailboxes, and in other community shared spaces. The balloons and posters were a visible signal of collective voter celebration by signaling voting was a civic activity that is tied to one's racial and local identity.

\section{Conclusion}

PATM effectively increased enthusiasm for voting and a community spirit of celebration around the elections in which it distributed boxes. Two of the four RCTs, both in Baltimore, generated measurable increases in turnout. Further studies are needed to determine why the results in Baltimore differ from those in Detroit and Philadelphia. One potential explanation stems from the stronger community links between the main organizations involved in the project—Black Girls Vote and Baltimore Votes_-to Baltimore. Because PATM began in Baltimore and the core team were located within the Baltimore area, they were able to more effectively coordinate the campaign locally compared to in the other cities. Our qualitative data suggest that more voters in Baltimore heard about PATM from one of these local organizations, making it feel more homegrown, compared to hearing about it on social media. At the same time, 
the RCTs in Detroit and Philadelphia were conducted in contexts of extreme polarization and unrest, including the pandemic, Black Lives Matter and continued episodes of police violence against Black people. Detroit and Philadelphia are battleground cities in battleground states. Further replications may find that PATM has only negligible effects in such contexts but that the successes in Baltimore are not (only) due to the local feel of those efforts but to the lower salience of those elections.

In August 2021, PATM signs were still visible in the windows of multiple Baltimore homes and businesses. The spirit of community celebrated by signs proclaiming "I love Baltimore so I vote" persisted long after the elections were over (See Figure 2). This visible display of the lasting power of PATM illustrates the understanding of the project by local residents as something that was part of their community. This sense of local ownership, facilitated by the participation of local groups, the local items in the Baltimore boxes, and the use of a local printer whose graphics were likely recognizable by local residents, may well be the magic recipe for a successful PATM campaign. Future iterations should focus on replicating that local community feeling.

Figure 2: 412 31 $^{\text {st }}$ Street, Baltimore, on August 12, 2021. 


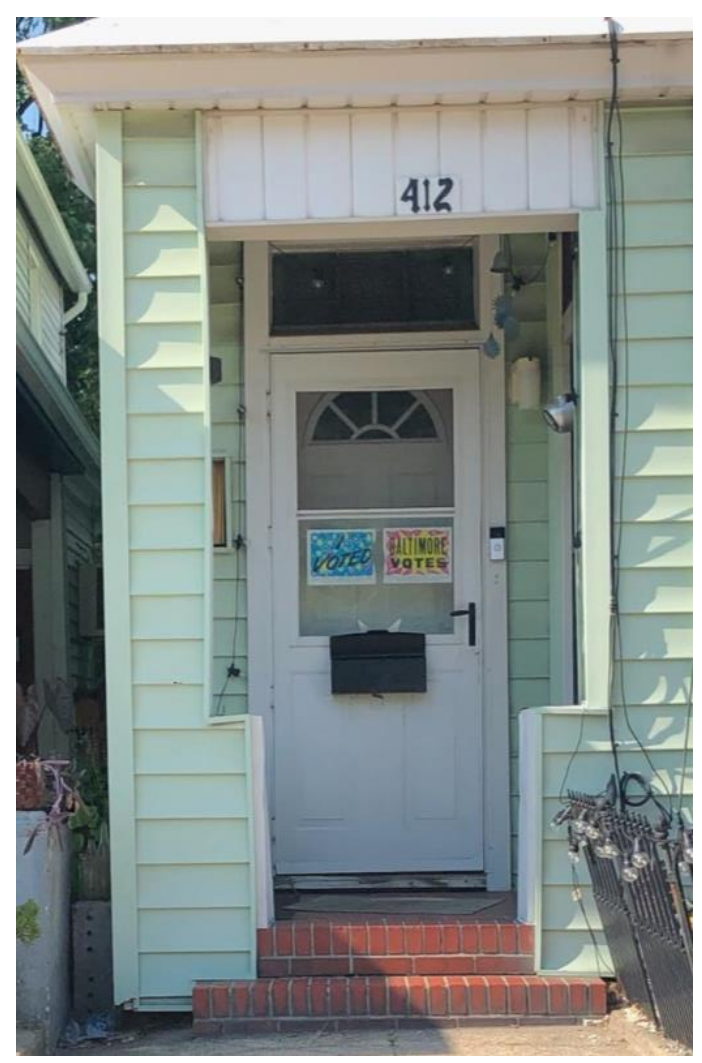

Note: Photo Credit, Sam Novey

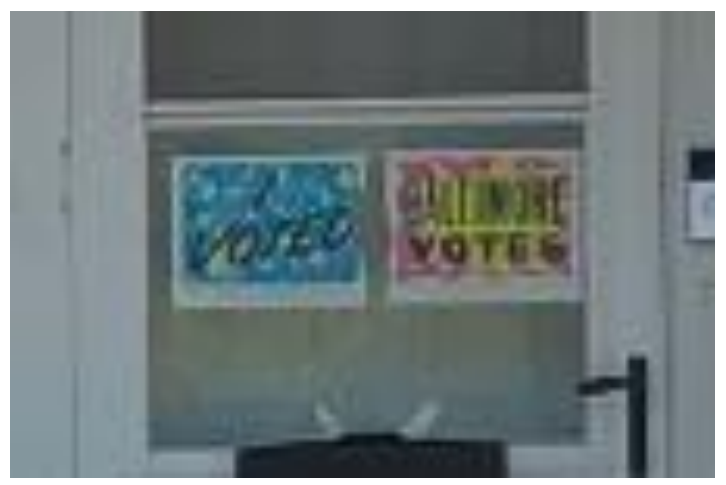




\section{References}

Addonizio, Elizabeth M., Donald P. Green, and James M. Glaser. 2007. "Putting the party back into politics: an experiment testing whether election day festivals increase voter turnout." $P S$ : Political Science \& Politics 40, 4: 721-727.

Azari, Julia, and Ebonya Washington. 2006. "Results from a 2004 Leafleting Field Experiment in Miami-Dade and Duval Counties, Florida." Unpublished Manuscript. Institution for Social and Policy Studies, Yale University.

Barber, Michael J., Christopher B. Mann, J. Quin Monson, and Kelly D. Patterson. 2014. "Online polls and registration-based sampling: A new method for pre-election polling." Political Analysis 22, 3: 321-335.

Blakemore, Erin. 2019. "Elections in Colonial America Were Huge, Booze-Fueled Parties." History.com, Nov. 25. https://www.history.com/news/colonial-america-election-day-parties

Cassel, Carol A. 2019. "Vote misreporting and black turnout studies in the U.S." Politics, Groups, and Identities 7, 3: 574-589.

Collins, Patricia Hill. 2000. Black Feminist Thought: Knowledge, Consciousness, and the Politics of Empowerment. New York, NY: Routledge.

Daniels, David D. III. 2020. "The Black Church has been getting 'souls to the polls' for more than 60 years." The Conversation.com, Oct. 30. https://theconversation.com/the-black-churchhas-been-getting-souls-to-the-polls-for-more-than-60-years-145996

Daniels, Ashley C.J. 2021. "Unlocking the power of the sister(hood) vote: exploring the opinions and motivations of NPHC sorority Black Women supporting Black women candidates." PhD thesis, Howard University.

Dawson, Michael C. 1994. Behind the Mule: Race and Class in African-American Politics. Princeton, NJ: Princeton University Press.

Dowe, Pearl K. Ford. 2016. “African American Women: Leading Ladies of Liberal Politics.” In Nadia E. Brown and Sarah Allen Gershon, eds., Distinct Identities: Minority Women in U.S. Politics. New York: Routledge, pp. 65-78.

Frymer, Paul. 1999. Uneasy Alliances: Race and Party Competition in America. Princeton, NJ: Princeton University Press.

García Bedolla, Lisa, and Melissa R. Michelson. 2012. Mobilizing Inclusion: Transforming the Electorate through Get-Out-the-Vote Campaigns. New Haven, CT: Yale University Press. 
Gerber, Alan S., and Donald P. Green. 2000. The Effects of Canvassing, Telephone Calls, and Direct Mail on Voter Turnout: A Field Experiment. American Political Science Review 94, 3: 653-663.

Giddings, Paula. 1988. In Search of Sisterhood: Delta Sigma Theta and the Black sorority Movement. New York: Harper Collins.

Giddings, Paula. 1984. When and where I enter: the impact of Black women on race and sex in America. New York: Amistad Publishing.

Gillespie, Andra Nicole. 2005. “Community, Coordination, and Context: A Black Politics Perspective on Voter Mobilization.” Ph.D. dissertation, Yale University.

Green, Donald P., and Melissa R. Michelson. 2009. "ACORN Experiments in Minority Voter Mobilization.” In Robert Fisher, ed., The People Shall Rule: ACORN, Community Organizing, and the Struggle for Economic Justice. Nashville, TN: Vanderbilt University Press, pp. 235-48.

Green, Donald P. 2004. "Mobilizing African-American Voters using Direct Mail and Commercial Phone Banks: A Field Experiment.” Political Research Quarterly 57, 2: 245-255.

Green, Donald P., and Oliver A. McClellan. 2017. "The effects of election festivals on voter turnout: a field experiment conducted during a presidential election." (July 9). http://dx.doi.org/10.2139/ssrn.2999305

Green, Donald P., and Oliver A. McClellan. 2020. "Election Festivals and Voter Turnout: An Overview of Recent Research.” (March 4). http://dx.doi.org/10.2139/ssrn.3548959

Harris-Lacewell, Melissa. 2004. Barbershops, Bibles, and BET: Everyday Talk and Black Political Thought. Princeton, NJ: Princeton University Press.

Harris, Fredrick C. 1999. Something Within: Religion in African-American Political Activism. New York: Oxford University Press.

Herron, Michael C., and Daniel A. Smith. 2012. "Souls to the Polls: Early Voting in Florida in the Shadow of House Bill 1355." Election Law Journal 11, 3: 331-347.

Higginbotham, Evelyn Brooks. 1993. Righteous Discontent: The Women's Movement in the Black Baptist Church, 1880-1920. Cambridge, MA: Harvard University Press.

Janes, Chelsea. 2020. "Kamala Harris, supported by a sea of sisters.” Washington Post, Oct 1. https://www.washingtonpost.com/politics/kamala-harris-aka-sorority/2020/10/01/801cf9de-fc4711ea-9ceb-061d646d9c67_story.html

Lee, Taeku. 2002. Mobilizing Public Opinion: Black Insurgency and Racial Attitudes in the Civil Rights Era. Chicago, IL: University of Chicago Press. 
McClerking, Harwood K., and Eric L. McDaniel. 2005. "Belonging and Doing: Political Churches and Black Political Participation.” Political Psychology 26, 5: 721-734.

McDaniel, Eric. 2008. Politics in the Pews: The Political Mobilization of Black Churches. Ann Arbor: University of Michigan Press.

Michelson, Melissa R., and Lisa García Bedolla. 2014. "Mobilization by Different Means: Nativity and GOTV in the United States." International Migration Review 48, 3: 710-727.

Murugesan, Anand. 2020. "Electoral Clientelism and Vote Buying." September 28. Oxford University Press.

https://oxfordre.com/politics/view/10.1093/acrefore/9780190228637.001.0001/acrefore9780190228637-e-1334

Nichter, Simeon. 2008. "Vote buying or turnout buying? Machine politics and the secret ballot." American Political Science Review 102, 1: 19-31.

Panagopoulos, Costas. 2013. "Extrinsic Rewards, Intrinsic Motivation and Voting." Journal of Politics 75, 1: 266-280.

Philpot, Tasha S., Daron R. Shaw, and Ernest B. McGowen. 2009. "Winning the Race: Black Voter Turnout in the 2008 Presidential Election." Public Opinion Quarterly 73, 5: 995-1022.

Ramírez, Ricardo, Romelia Solano, and Bryan Wilcox-Archuleta. 2018. "Selective Recruitment or Voter Neglect? Race, Place, and Voter Mobilization in 2016." Journal of Race, Ethnicity and Politics 3, 1: 156-184.

Riker, William H., and Peter C. Ordeshook. 1968. "A Theory of the Calculus of Voting." American Political Science Review 62, 1: 25-42.

Shineman, Victoria. 2018. "If You Mobilize Them, They Will Become Informed: Experimental Evidence that Information Acquisition Is Endogenous to Costs and Incentives to Participate." British Journal of Political Science 48, 1: 189-211.

Sinclair, Betsy, Margaret McConnell, and Melissa R. Michelson. 2013. "Local canvassing: The Efficacy of Grassroots Voter Mobilization.” Political Communication 30, 1: 42-57.

Smooth, Wendy G. 2018. "African American women and electoral politics: The core of the new American Electorate.” In Susan J. Carroll and Richard L. Fox, eds., Gender and Elections: Shaping the Future of American Politics. New York: Cambridge University Press, pp. 171-197.

Strauss, Anselm, and Corbin, Juliet. 1998. Basics of qualitative research: Techniques and procedures for developing grounded theory (2nd ed.). Thousand Oaks, CA: Sage. 
Vroman, Mary Elizabeth. 1965. Shaped to its purpose: Delta Sigma Theta, the first fifty years. New York: Random House.

Vicente, Pedro C. 2014. "Is Vote Buying Effective? Evidence from a Field Experiment in West Africa." The Economic Journal 124, 574: F356-F387.

Walton, Hanes. 1985. Invisible Politics: Black Political Behavior. Albany, NY: State University of New York Press.

Walton, Hanes, and Robert C. Smith. 2012. American Politics and the African American Quest for Universal Freedom (6 $\left.{ }^{\text {th }} \mathrm{Ed}\right)$. New York: Longman.

White, Ismail K., and Chryl N. Laird. 2020. Steadfast Democrats: How Social Forces Shape Black Political Behavior. Princeton, NJ: Princeton University Press.

Zinn, Maxine Baca. 1979. "Field research in minority communities: Ethical, methodological and political observations by an insider." Social Problems 27, 2: 209-219. 